\title{
Individual costs and societal benefits: the privacy calculus of contact-tracing apps
}

\author{
Feanette Carlsson Hauff and Fonas Nilsson \\ Department of Marketing, School of Business, Economics and Law, University of Gothenburg, Gothenburg, Sweden
}

\begin{abstract}
Purpose - During 2020, governments around the world introduced contact-tracing apps to fight the COVID-19 pandemic. In order for contacttracing apps to be efficient tools in combatting pandemics, a significant proportion of the population has to install it. However, in many countries, the success of apps introduced during the COVID-19 pandemic has been limited due to lack of public support. This paper aims to better understand why consumers seem unwilling to install and use a contact-tracing app.

Design/methodology/approach - In this study, the authors test a number of determinants hypothesized to influence acceptance of contact-tracing apps based on the theory of privacy calculus (Dinev and Hart, 2006). Both perceived privacy concerns, as well as perceived hedonic, utilitarian and pro-social benefits are included. The hypotheses are tested through SEM analysis on a representative sample of 1,007 Swedish citizens.

Findings - The results indicate significant privacy concerns with using contact-tracing apps. However, this is to some extent offset by perceived hedonic and pro-social positive consequences of using the app. This study further shows that a general positive attitude towards innovation increases acceptance of the app. Originality/value - The study contributes to research on consumer privacy, both in general in its application of the calculus model but also specifically in the context of contact-tracing apps. Moreover, as the results highlight which aspects that are important for consumers to accept and install an app of this kind, they also represent an important contribution to policymakers in countries around the world.
\end{abstract}

Keywords Consumer privacy, COVID-19, Privacy calculus, Contact-tracing apps, Pro-social benefits

Paper type Research paper

\section{Introduction}

The COVID-19 pandemic has brought a number of consequence to societies all over the world. Not only has the pandemic had devastating medical effects, with the loss of millions of lives. It has also triggered a number of responses from governments, such as lock-downs of whole sections of society. From a consumer perspective, the lock-downs have further implied that many individuals have been forced to change their daily routine in a previously unforeseen magnitude.

One of the initiatives that governments have introduced to fight the pandemic, have been so called digital contact-tracing apps, aiming to fight the virus by keeping track of potential bearers. As early as in March 2020, Singapore launched the tracing app TraceTogether, and in May the Apple-Google exposure notification system was implemented in the first of many countries (Zastrow, 2020). As regards privacy, the early apps and the apps built on the Apple-Google tech take a differing stance. The early apps collect information regarding the infection of an individual and report it to the authorities for identification, hence requiring access to unique individual information (Sharma and Bashir, 2020). The Apple-Google notification system, on the other hand, matches anonymous lists of users to lists of reported COVID-19 cases and notifies potential close encounters without revealing the identity of

The current issue and full text archive of this journal is available on Emerald Insight at: https://www.emerald.com/insight/0736-3761.htm

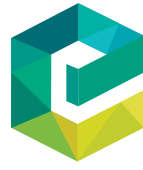

Journal of Consumer Marketing

40/2 (2023) 171-180

Emerald Publishing Limited [ISSN 0736-3761]

[DOI 10.1108/JCM-03-2021-4559] either party. This is in line with statements from the European Data Protection Board (Council of Europe, 2020) where digital contact tracing is to avoid building on location data (Global positioning system generated data for instance). The fact that both the European Data Protection Board and the AppleGoogle platform explicitly addresses privacy issues is interesting - but does not guarantee that individuals will perceive it as "safe" from a privacy perspective.

The fact that contact-tracing apps sometimes require individual information has sparked a debate concerning possible violations of integrity (Sharma and Bashir, 2020). These privacy concerns are important as they may constitute a concrete impediment when trying to persuade citizens to use the technology available. From a legal perspective, many privacy laws such as the European General Data Protection Regulation (GDPR) contain exceptions for health emergencies, implying that collection and storage of personal information could well be in line with current regulation (Birnbaum and Spolar, 2020). However, given that use of contact-tracing apps is voluntary, as in for example Germany, France and Britain, perceived

(C) Jeanette Carlsson Hauff and Jonas Nilsson. Published by Emerald Publishing Limited. This article is published under the Creative Commons Attribution (CC BY 4.0) license. Anyone may reproduce, distribute, translate and create derivative works of this article (for both commercial and non-commercial purposes), subject to full attribution to the original publication and authors. The full terms of this license may be seen at http:// creativecommons.org/licences/by/4.0/legalcode

Funding: Both Carlsson Hauff and Nilsson are grateful for funding from Lansforsakringars Forskningsfond, P6/18.

Received 30 March 2021

Revised 4 June 2021

Accepted 27 July 2021 
privacy concerns are likely to decrease the willingness of individuals to use them. This fact is concerning as the success of contact-tracing apps requires mass acceptance: more than half of a country's population will have to install, accept and use an introduced app for the positive consequences to take effect (Hinch et al., 2020).

These requirements practically mean that the success of digital contact-tracing apps relies on a thorough understanding of consumers' willingness to accept and use the app in question. Hence, understanding the drivers and considerations of the individual is of paramount importance: what are the determinants of consumer willingness to install and use a contact-tracing app? In the current study, we test whether factors such as individuals' perceived usefulness of contact-tracing apps, a general attitude towards technological innovation and finally individual's concerns regarding the possible violation of privacy may act as determinants of willingness to use the app. As a result, the paper contributes with an understanding of drivers and potential obstacles of installing and using a contact-tracing app. By highlighting the interplay between individual costs and societal benefits, we further contribute with insights on how the theory of privacy calculus can be augmented to better understand how privacy concerns are weighed by consumers against potential benefits. On a practical note, this contributes to an understanding of consumer acceptance of new digital solutions, beyond the context of trace apps, with perceived privacy implications. These insights may be used by policymakers to communicate effectively with the general public.

\section{Theoretical overview}

\section{Privacy calculus framework}

With the increased use of mobile devices it is not surprising that the issue of privacy and preservation of personal information has gained attention (Wottrich et al., 2019). The acceptance and use of apps and mobile devices, despite privacy implications, may stem from a calculated judgement where consumers perceive the benefits of usage to outweigh the privacy costs (Bagozzi, 1975). This judgement, in short, is the cornerstone of exchange theory (Bagozzi, 1975), a framework that has been frequently applied to understand privacy-related consumer decision (Culnan and Bies, 2003). The model inherent in this exchange framework practically involves a privacy calculus, i.e. a weighing mechanism, where perceived benefits are evaluated against perceived costs (Dinev and Hart, 2006). In our setting, this implies that the consumer is assumed to perform a judgment of what a use of the contact-tracing app will involve.

For the purpose of consumer-oriented research regarding privacy, the model of privacy calculus has been a fruitful way to view individuals' decisions concerning the willingness to disclose personal information, and the decision to use certain digital apps. Acknowledging that the perceived negative consequences, such as privacy concern, or the perceived benefits such as ability to personalize or economize from offerings, differ among consumers, the calculus framework enables an understanding of individual behavior with privacy-related consequences. The versatility of the calculus model is further visible in its many applications: mobile applications (Wang et al., 2020), location based online services (Zhao et al., 2012) and online shopping (Dinev and Hart, 2006).

The fact that individuals frequently choose to use digital apps or digital services implying disclosure of personal information when at the same time stating a marked privacy concern, has given rise to a stream of literature on the so called privacy paradox (Norberg et al., 2007). This paradox is in effect a mismatch between the stated attitude towards privacy and the subsequent observed privacy-related behavior. Several studies have further focused on the role of privacy concerns when attempting to explain individuals' privacy-related behavior (Martin and Murphy, 2017); a stance that is not without problems (Pomfret et al., 2020). Measuring privacy concerns will not capture but a small aspect of privacy attitudes, an aspect that also by nature will be defined by the context within which it exists (Pomfret et al., 2020). The frequent use of privacy concerns as a proxy for privacy attitudes has even been brought forward as one explanation of the privacy paradox, i.e. the observed attitudebehavior gap (Dienlin and Trepte, 2015). The present paper takes a different approach and focuses on the perceived benefits inherent in the calculus model. We suggest that, just as the observed paradox may stem from privacy concerns being insufficiently measured, a rudimentary treatment of the perceived usefulness would potentially have the same effect. In the particular context of contact-tracing apps, we suggest that the inclusion of so called prosocial benefits, in other words the perception that my use of a contact-tracing app will be beneficial for others, may add important input to individuals' perceived benefits.

The model used in the present study is presented in Figure 1.

\section{Influence of privacy concerns}

One of the potential negative consequences inherent in the privacy calculus stems from the fact that consumers are asked to disclose information about themselves, and the potential loss of control over the information that this entails (Culnan, 1993). While different technical solutions for these apps exist, there is an ongoing discussion about the extent of disclosure needed by the user (for example, some claim that individual location data is still being collected with the Apple-Google technology; Muoio, 2020). Hence, the build-up of further privacy concern evolves around beliefs about which entities - organizations or individuals - have access to disclosed information and assumptions concerning the use of this information (Dinev and Hart, 2006). The level of individual privacy concern has previously been found to constitute an important factor regarding the decision to disclose personal information (Dinev et al., 2012). In a meta-analysis of 166 published privacy studies, privacy concern was negatively connected to both willingness to disclose personal information and actual disclosure behavior (Baruh et al., 2017).

Privacy concern may be decomposed into several components; an element of perceived vulnerability highlighting the importance of perceived risk and an element of perceived control (Beke et al., 2018). Starting with perceived privacy risk, it involves the expectation of losses due to disclosure of personal information (Xu et al., 2011). Just as level of perceived risk is generally associated with the possibility of a third party acting opportunistically, perceived privacy risk evolves around the situation where the collector of personal information acts in ways undesirable for the disclosing individual. Privacy control, on the other hand, refers to the individuals' perception regarding ability to determine who will be able to view the information disclosed ( $\mathrm{Xu}$ et al., 2011). This perception of control has in several studies been deemed to be negatively associated with the fear of a future privacy invasion, and hence 
Figure 1 Conceptual model of determinants of consumers' willingness to use contact-tracing apps

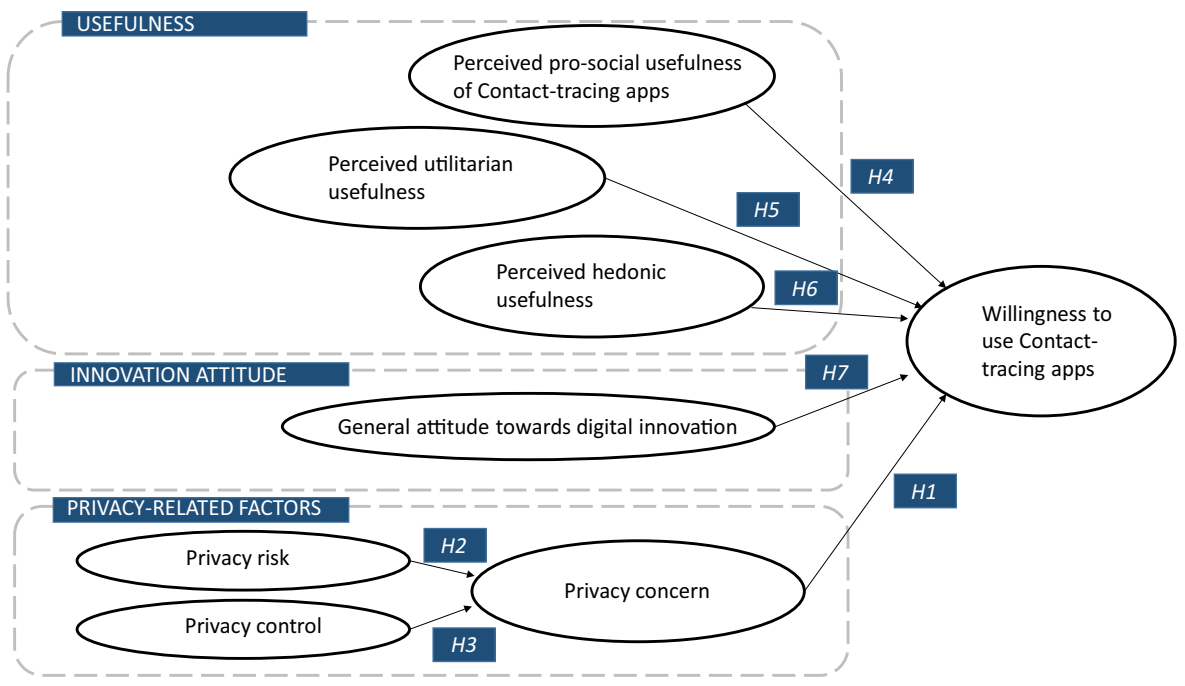

that increased levels of privacy control leads to lower levels of privacy concern (Culnan and Armstrong, 1999).

In all, privacy concerns have been found to have a negative effect on consumer willingness to disclose information, rendering the following hypotheses:

H1. Privacy concerns regarding contact-tracing apps will have a negative impact on consumer willingness to use the apps in question.

H2. Privacy concerns will be positively affected by perceived riskiness of disclosing personal information.

H3. Privacy concerns will be negatively affected by perceived control as regards disclosed personal information.

\section{Influence of attitudes toward adoption of innovations}

When it comes to adopting a new behavior, such as installing and using a contact-tracing app, it seems reasonable that the general attitude towards technical innovation should be of interest. In the literature, we find connections between attitude towards innovation and both concerns and benefits perceived when using digital apps. Starting with the perceived benefits, the technology acceptance model (TAM; Davis, 1989) explicitly models "perceived usefulness" as having a positive influence on usage of new technologies (TAM; Davis, 1989). On the other hand, the stated beliefs towards using a new technology is also considered to be influenced by the level of technological anxiety (Lee, 2009). High anxiety individuals have limited self-confidence when using new technology, and tend to focus on the inherent complexity and potential risks of the task at hand (Parayitam et al., 2010). Several studies have further introduced the individual characteristic of enthusiasm, or affinity, perceived when dealing with technology devices (Franke et al., 2019). All in all, it is likely that attitude towards innovation is connected to willingness to use a new technology in the form of an app, such as the contact-tracing apps introduced in order to curb the spreading of COVID-19.

H4. A positive attitude towards digital innovations will have a positive impact on willingness to use contact-tracing apps.
Influence of perceived altruistic, hedonic and utilitarian usefulness

Inherent in the duality of the privacy calculus model are the potential benefits, or perceived usefulness of using a contact-tracing app. The use of a certain digital service is hence not evidence that the individual does not perceive it as risky, nor that this service does not imply a possible breach of integrity, but rather that these risks are "endured" because of key benefits (Lee et al., 2013).

These perceived types of usefulness may come in different shapes and levels; they may be general and utilitarian, such as promoting economic and informational solutions for the user and implying increased productivity (de Kerviler et al., 2016) or they may constitute a more general emotional value, incorporating feelings of fun and joy (Pizzi et al., 2019). Interestingly, hedonic benefits has proven to be a stronger motivator than the utilitarian benefits (Scarpi, 2012). However, on top of these more general utilitarian and emotional benefits, part of the specific potential usefulness of a contact-tracing app may be perceived societal benefits, i.e. a possibility for the user to contribute to a general tracing coverage and inform others of possible infection (Trang et al., 2020). This may either be traced to a willingness to act in accordance with societal norms but also from sheer altruism (White and Peloza, 2009). Thus, understanding how consumers perceive the pro-social benefits of contact-tracing apps may be an important determinant of willingness to use such an app.

To sum up, benefits may exist on different levels: they may be general (both utilitarian and emotional) and associated with use of smartphones, or they may be more specific, such as the prosocial benefits of using a contact-tracing app. In understanding consumers' willingness to use a contact-tracing app, both the perceived general benefits as well as the more specific benefits associated with contact-tracing apps will have to be understood.

Against this background, the following hypotheses regarding the impact of perceived general and specific benefits on consumer willingness to use contact-tracing apps are put forth:

H5. Perceived specific pro-social usefulness of using contacttracing apps will have a positive impact on willingness to use the apps in question. 
H6. Perceived general utilitarian usefulness of using smartphones will have a positive impact on willingness to use the apps in question.

H7. Perceived general hedonic usefulness of using smartphones will have a positive impact on willingness to use the apps in question.

\section{Method}

\section{Sample and data collection}

Data was collected using a web-based survey to Swedish citizens. Sweden's response to the COVID-19 pandemic has been described as "more relaxed" than many other countries, with its economy largely remaining open during 2020. Another difference between Sweden and many comparable countries is that no contact-tracing app has been introduced in Sweden. One of the arguments brought up against the introduction of such apps has been the privacy consequences to individual citizens.

The sample of respondents was randomly selected from members of a major European web-panel hosted by the marketing research firm Norstat. The panel consists of approximately 85,000 people, recruited by the company to be representatives of the general Swedish population. As such, the panel does not allow for members to join the panel on their own initiative. Instead they have to be actively recruited by the company to ensure that not only groups who see joining a panel as a source of income join it.

The survey was sent out in June 2020. In order to answer the survey, the respondents had to have some familiarity with internet services and four responses were removed as a result of this requirement. The final usable sample consisted of 1,007 respondents. The sample consisted of an equal share of men and women with an average age of 45 (S.D. = 14.3, range 1870 years). About $44 \%$ of the sample had a university degree and the most frequently stated income bracket was between US $\$ 35,000$ to US $\$ 47,0000$ per year (28.6\% of respondents).

\section{Measures}

On top of basic socio-demographic data, the survey contained a number of questions on privacy concerns, perceived benefits of contact-tracing apps, attitudes to innovations and willingness to use contact-tracing apps. A list of the items is presented in Table 1.

To measure the privacy concern construct we used seven items, combining both general privacy concern (Malhotra et al., 2004) and specific privacy concern ( $\mathrm{Xu}$ et al., 2011). We further measured the construct of privacy risk with four items (based on Xu et al., 2011) and privacy control with three items (adapted from Pavlou and Chellappa, 2001 and Xu et al., 2011). Given that we wanted to capture different levels of the different usefulness constructs, we measured these in somewhat differing ways. As for utilitarian usefulness and emotional usefulness, we framed the items in terms of benefits of general smartphone usage. Here, we followed previous research and measured the construct of utilitarian usefulness using nine items, capturing both usefulness in terms of increased convenience (Childers et al., 2002), economic usefulness (MimouniChaabane and Volle, 2010) and informational usefulness (Mimouni-Chaabane and Volle, 2010). General hedonic usefulness was measured using three items capturing enjoyment (Venkatesh et al., 2012). With regard to the pro-social benefits, we wanted to measure these specifically to the app in question. As there is little research on pro-social benefits in this context, these benefits were measured using three items developed specifically for this survey, capturing respondents willingness to disclose data for the benefit of the common good. Prior to using the scale, a small number of experts were consulted to ensure content validity of the items. Finally, the general attitude towards new innovations was measured using a single item that asked respondents how prone they were to use new internet and webbased services. All items in the survey were measured on a fivepoint Likert-scale, anchored by completely disagree (1) and completely agree (5).

To measure the dependent variable we used three items capturing the willingness of the respondent to use the contacttracing app. Again, the answers on five-point Likert-scales, anchored by "would not be willing to use the app" and "would definitely be willing to use the app".

\section{Measurement model fit}

Prior to testing the hypotheses, validity and reliability of the data-set was ensured. The dataset was checked for kurtosis or skewness, with no violations detected. A CFA, using AMOS, was performed, presenting reasonable fit for the measurement model $(\mathrm{CMIN} / \mathrm{df}=3,56 ; \mathrm{GFI}=0.925 ; \mathrm{RMSEA}=0.048$; $\mathrm{NFI}=$ $0.955 \mathrm{CFI}=0.968)($ Kline, 2005). All indicators lie within acceptable ranges bar the lack-of-fit indicator CMIN/df. This measure, however, is sensitive to sample size (Gupta and Singh, 2014/15). Three items regarding utilitarian benefits (time-related usefulness) were dropped due to low standardized regression weights. The inter-construct correlations were generally low, except for the correlation between the hedonic and the utilitarian usefulness-items. This will be taken into account by allowing the constructs to correlate in the SEM model.

\section{Validity, reliability and multivariate assumptions}

Table 2 shows no issues with reliability. C.R.-values in the table are all over 0.7 , and the MaxR-values are all above 0.8 . We further present adequate convergent validity, with AVE-values larger than 0.5 for all constructs. The square-root of the AVE's is larger than any of the inter-factor correlations further indicating discriminate validity. The discriminant validity is also strengthened with AVE $>$ MSV for all variables.

Common method bias was addressed by running a factor analysis with one single factor. The unrotated factor solution (principal component analysis) explained $27.1 \%$ of the variance, implying that there is no imminent problem with an underlying common factor (Fuller et al., 2016). A Cook's distance test was further performed to detect possible outliers, and two respondents were removed due to abnormal patterns. The sample size after the two respondents were removed was 1005. The collinearity diagnostics revealed no issues with the tolerance diagnostics. However, as for the VIF-factors, Perceived risk and Privacy concern both had scores of around 3.5. This is an indication of multicollinearity, which in the model will be dealt with by allowing the variables to co-vary. 
Table 1 The Items in the survey

\begin{tabular}{|c|c|c|c|}
\hline Construct/item & M & SD & Cronbach alpha \\
\hline Privacy concern & 3.23 & 0.94 & 0.927 \\
\hline $\begin{array}{l}\text { Compared to others, I am more sensitive about the way online companies handle my } \\
\text { personal information }\end{array}$ & 2.78 & 1.12 & \\
\hline To me, it is most important to keep my privacy intact from online companies & 3.15 & 1.12 & \\
\hline I am concerned about threats to my personal privacy today & 3.09 & 1.16 & \\
\hline I am concerned that the information I submit to this website could be misused & 3.36 & 1.12 & \\
\hline I am concerned that others can find private information about me from this website & 3.37 & 1.16 & \\
\hline $\begin{array}{l}\text { I am concerned about providing personal information to this website, because of } \\
\text { what others might do with it }\end{array}$ & 3.40 & 1.12 & \\
\hline $\begin{array}{l}\text { I am concerned about providing personal information to this website, because it } \\
\text { could be used in a way I did not foresee }\end{array}$ & 3.45 & 1.13 & \\
\hline Privacy risk & 3.23 & 0.91 & 0.882 \\
\hline In general, it would be risky to give personal information to this website & 3.37 & 1.07 & \\
\hline $\begin{array}{l}\text { There would be high potential for privacy loss associated with giving personal } \\
\text { information to this website }\end{array}$ & 3.25 & 1.05 & \\
\hline Personal information could be inappropriately used by this website & 3.41 & 1.04 & \\
\hline $\begin{array}{l}\text { Providing this website with my personal information would involve many } \\
\text { unexpected problems }\end{array}$ & 2.90 & 1.05 & \\
\hline Privacy control & 1.98 & 0.99 & 0.836 \\
\hline $\begin{array}{l}\text { I am aware of the exact nature of information that will be controlled during a } \\
\text { transaction with this vendor }\end{array}$ & 2.14 & 1.09 & \\
\hline $\begin{array}{l}\text { I believe I can subsequently verify the information I provide during a transaction } \\
\text { with this vendor }\end{array}$ & 1.91 & 0.99 & \\
\hline I think I have control over what personal information is released by this website & 1.90 & 1.01 & \\
\hline Utilitarian usefulness & 4.04 & 0.89 & 0.943 \\
\hline Using my smartphone would allow me to get information about stores and products & 4.18 & 0.96 & \\
\hline Using my smartphone would allow me to access product price comparisons & 4.19 & 0.98 & \\
\hline $\begin{array}{l}\text { Using my smartphone would allow me to get useful information to make better } \\
\text { shopping decisions }\end{array}$ & 4.08 & 1.02 & \\
\hline Using my smartphone would allow me to do my shopping at a lower financial cost & 4.04 & 1.01 & \\
\hline Using my smartphone would allow me to save money & 3.85 & 1.06 & \\
\hline Using my smartphone would allow me to take advantage of promotional offers & 3.91 & 1.03 & \\
\hline Using my smartphone would allow me to save time during my shopping. (removed) & $(3.77)$ & $(1.03)$ & \\
\hline Using my smartphone would make my shopping less time consuming. (removed) & (3.49) & $(1.10)$ & \\
\hline Using my smartphone would be a convenient way to do shopping. (removed) & $(3.60)$ & $(1.10)$ & \\
\hline Hedonic usefulness & 2.88 & 0.78 & 0.923 \\
\hline Using my smartphone would be enjoyable & 3.68 & 0.97 & \\
\hline Using my smartphone would be entertaining & 3.51 & 1.07 & \\
\hline Using my smartphone would be fun & 3.50 & 1.07 & \\
\hline Pro-social usefulness & 2.88 & 1.18 & 0.946 \\
\hline $\begin{array}{l}\text { I get a good feeling from knowing that data about me may be used for the benefit of } \\
\text { others, e.g. in stopping the spreading of diseases }\end{array}$ & 2.88 & 1.22 & \\
\hline $\begin{array}{l}\text { It's good know that data regarding the whereabouts of my cell phone may be crucial } \\
\text { in order to prevent the spreading of diseases }\end{array}$ & 2.90 & 1.25 & \\
\hline $\begin{array}{l}\text { An important side effect of my usage of mobile phones is that the control of the } \\
\text { spreading of the disease may be carried out in a more exact way }\end{array}$ & 2.87 & 1.24 & \\
\hline $\begin{array}{l}\text { How innovation-prone, i.e. keen on using e.g. new internet-based apps and services, } \\
\text { would you say that you are? }\end{array}$ & 3.14 & 1.05 & \\
\hline Willingness-to-use control-tracing apps & 2.64 & 1.35 & 0.963 \\
\hline $\begin{array}{l}\text { Regardless of whether you have used the digital app, would you be willing to use a } \\
\text { contact- tracing app that inform authorities of your whereabouts }\end{array}$ & 2.69 & 1.41 & \\
\hline $\begin{array}{l}\text { Regardless of whether you have used the digital app, would you give continuous } \\
\text { information regarding bodily information to authorities }\end{array}$ & 2.59 & 1.40 & \\
\hline $\begin{array}{l}\text { Regardless of whether you have used the digital app, would you inform authorities } \\
\text { about persons with whom you have been in close contact }\end{array}$ & 2.65 & 1.38 & \\
\hline
\end{tabular}




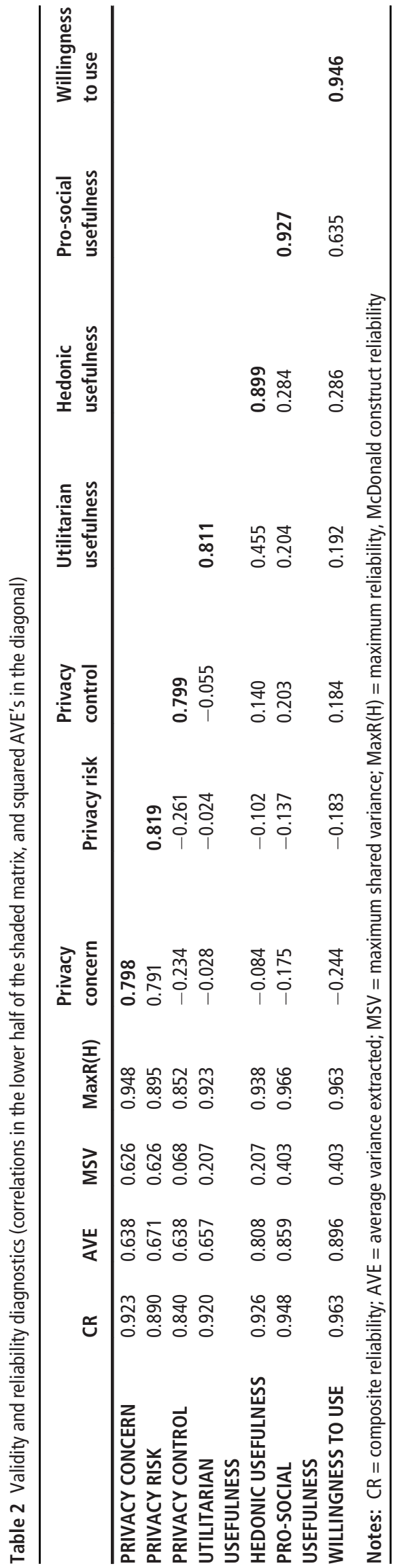


Table 3 Standardized path estimates

\begin{tabular}{lrr}
\hline Hypothesized relationship & Coefficient & Sig. \\
\hline H1: Privacy concern $\rightarrow$ Willingness to use CTA & -0.291 & $<0.001$ \\
H2: Privacy risk $\rightarrow$ Privacy concern & 0.565 & $<0.001$ \\
H3: Privacy control $\rightarrow$ Privacy concern & -0.010 & 0.466 \\
H4: Attitude towards technology $\rightarrow$ Willingness to use CTA & 0.182 & $<2$ \\
H5: Pro-social usefulness $\rightarrow$ Willingness to use CTA & 0.741 & $<0.001$ \\
H6: Utilitarian usefulness $\rightarrow$ Willingness to use CTA & 0.049 & 0.001 \\
H7: Hedonic usefulness $\rightarrow$ Willingness to use CTA & 0.103 & 0.276 \\
H. & & 0.027
\end{tabular}

Note: CTA: Contact-tracing apps

\section{Results}

In order to evaluate the influence of the independent variables on willingness to install a contact-tracing app, we used structural equation modelling. The resulting coefficients and significance values is presented in Table 3. The model fit was again acceptable $(\mathrm{CMIN} / \mathrm{df}=5.054 ; \mathrm{GFI}=0.988 ; \mathrm{RMSEA}=$ 0.064; $\mathrm{NFI}=0.981: \mathrm{CFI}=0.985)(\mathrm{Kline}, 2005)$ again bar the $\mathrm{CMIN} / \mathrm{df}$.

In $H 1-H 3$ we tested the influence of privacy concerns on willingness to use a contact-tracing app. As can be seen in Table 3, the standardized path estimates indicated a significant impact of privacy concerns on willingness to use a contacttracing app, as hypothesized in $\mathrm{H}_{1}$ (coeff $=-0.291 ; p<0.001$ ). These concerns were further found to stem primarily from the perceived riskiness (lending support to $H 2$; coeff $=0.565$; $p<$ 0.001 ) but not from privacy control (rejecting $H 3$; coeff $=$ $-0.010 ; p=0.466)$. Further, a strong positive effect of innovation attitude on the willingness to use contact-tracing apps was found, enabling us to accept $H 4$ (coeff $=0.182$; $p<$ $0.001)$. As for the drivers of willingness to use the contacttracing apps, the results indicated a strong positive influence of pro-social usefulness, i.e. a willingness to use the apps stemming from an urge to contribute to a greater societal good, along with H5 (coeff $=0.741 ; p<001$ ). However, no significant impact of more general, utilitarian perceived usefulness was found, leading us to reject $H 6$ (coeff $=0.049 ; p=0.276$ ). Finally, the results indicate a positive influence of hedonic usefulness, in line with $H 7$ (coeff $=0.103 ; p=0.027)$.

\section{Discussion}

This paper started out with the aim of understanding why people seem unwilling to install and use contact-tracing apps. Used successfully, these apps may be a tremendous tool to fight the current (and future) pandemic(s), and are likely to reduce suffering and loss of lives. In many ways, from a public-policy standpoint, this question can be turned towards design and communication; how can public-policy-makers best design an app, and communicate with their publics, to ensure a widespread acceptance?

To address this aim, we tested a number of determinants of willingness to install contact-tracing apps, guided by the theoretical lens of privacy calculus. As inherent in the calculus model, the behavior to use contact-tracing apps is viewed as a weighing of positive and negative consequences. In our tested model, we found evidence of impeding influence stemming from privacy-related concerns and driving factors being various types of perceived benefits and a positive attitude towards new technology.

Starting with the determinants stemming from privacy concerns, our results indicated that privacy-related risk was an important cause of privacy concerns, whereas privacy control did not have a counter-balancing effect. Privacy-related risks relates to the collector of personal information acting in ways undesirable for the disclosing individual, whereas privacy control focus on the ability to determine the use of information disclosed. Thus, the results indicated a more tangible riskcomponent, at least in this context, which is in line with previous results referred to by Beke and colleagues (Beke et al., 2018).

Regarding the influence of privacy concerns, the results indicated a negative relationship between concerns and willingness to use contact-tracing apps. This negative relationship was expected and largely mirror results in other studies (Dinev et al., 2012). This shows that potential loss of integrity associated with disclosure of personal information is something that is taken into account by the individual when deciding whether to use the app. Interesting here, given the varying level of privacy considerations in the apps available, is that consumers' assumption apparently is that privacy issues are at stake when installing this type of app, and thus matter on a general level. The discussion on if- and if so, how much, data is disclosed in the apps (Muoio, 2020), may hence be less important here. Maximizing the use of contact-tracing apps accordingly involves accommodating general privacy-related concerns and general privacy-related risks of individuals, regardless of amount and sensitivity of data actually collected.

A further determinant tested in the model was individual attitude towards adopting new technologies. Contact-tracing apps are a new technological development, and as such, may be causing both feelings of risk or unease, or an enthusiasm with using it. We found that people who felt uneasy about using new technologies also seemed less willing to use apps of this kind, mirroring the results of, among others Lee (2009). Thus, maximizing the use of contact-tracing apps accordingly involve minimizing the insecurity regarding what the app does and how it does it.

The final set of determinants in the study focused on the perceived usefulness of the apps in question. We tested three types of usefulness of contact-tracing apps; hedonic, utilitarian, and pro-social. We found that the general hedonic usefulness, i.e. the "fun" of using smartphones, was a significant determinant of willingness to use contact-tracing apps. The 
utilitarian benefits of using smartphones did however not have a significant impact. The relative importance of hedonic benefits over more utilitarian benefits, as noted by Scarpi (2012) was hence confirmed in our study. The strongest determinant, however, were the specific pro-social perceived benefits connected to the app, pointing at usage of apps being associated with the achievement of a greater good. The feeling that the use of contact-tracing apps, notwithstanding the possible negative impact as regards integrity of personal information, might help control the disease and hence make life better for other people was thus important. Compared to the results above, where the fun and the technology enthusiasm had a positive impact on willingness to use the app, this result holds some interesting implications. First, we observe that the benefits inherent under the label "pro-social benefits" are specific in nature, i.e. they pertain to the unique situation caused by the pandemic. Second, and maybe more interestingly, they are not related to the individual. It is hence not the benefit of the single citizen that is at stake here, but rather the combined utility on a societal level.

\section{Contributions}

The current study contributes to the literature in a number of ways. First off, this study contributes to the general literature on consumer privacy concerns in general (Baruh et al., 2017), with a specific focus on privacy calculus research (Dinev and Hart, 2006). Many previous studies have focused on privacy concern, while the current study extends this by incorporating variants of perceived usefulness. The result is a better understanding of the tradeoff of privacy-related behavior, with downsides in terms of privacy and upsides in terms of benefits. The application of this go beyond the current context, and could be applied to many different behaviors with privacy implications.

More specifically, to the context of contact-tracing apps, our results further contribute in that they highlight a calculus mechanism consisting of an individual downside, i.e. privacyrelated hindering factors, and a (primarily) societal benefit. There is a price to be paid for the individual deciding to disclose his or her positioning data through a contact-tracing app, and this perceived cost is offset not by an individual benefit but mainly by a perceived pro-social benefit: the ability to use the information gathered for the societal purpose of hindering the spreading of the disease. This is an important augmentation of the original privacy calculus mechanism, and the connection between privacy and pro-social benefits serves as a reminder that individuals may be motivated also by pro-social, or altruistic factors. This further implies that research on consumer privacy could look to the literature on social dilemmas to generate insights. This literature often focus on general behaviors with individual costs and social benefits, such as environmentally friendly consumption and donation behavior, and may hence be useful for future studies on consumer privacy.

\section{Practical implications}

On top of contributions to the literature, the study has a number of important implication for public policy. Closely related to the general aim of the study, to understand the reluctance among people to install a contract-tracing app, is the public policy question of how to design and communicate regarding a contact-tracing app to ensure widespread acceptance and use of the app. Given that the success of this type of app is contingent on a large percentage of the population actually using it, this question is more important than in many other contexts.

The emerging calculus from this study, with an individual cost in terms of privacy concerns and gains stemming primarily from pro-social benefits lends some concrete recommendations. First, it is important for public-policy makers to reduce the concern of privacy violations when enabling the app to use geopositioning data. Examples of this could be stressing that the usage of personal information is limited to the collecting party, or to refer to standards such as the European GDPR. This would likely have to be communicated regardless of the extent of sensitive data collected, as skeptical and distrusting people are likely to think that data collection may continue despite communication arguing otherwise.

Public policy-makers would also do well in including peoples' unease with adopting new technologies, both in the design and in communication of the app. The app would have to be easy to use, and communication could center around how the app works, without going into technical jargon. General communication may start in a recognition that new technologies are difficult to understand for many people.

Finally, the results of the study highlight pro-social motivation as important. The greater good could thus be highlighted in communication towards the public, with the message that an individual usage of the app creating a body of observations being crucial in order to curb the disease.

\section{Limitations and future research}

The context of the study, i.e. the ongoing COVID-19 pandemic is both a limitation and a strength. The study could be regarded as bounded by the specific pandemic situation and hence limited in its ability to provide generalizations. This would imply that the influence of the perceived pro-social benefits must be understood in relation to the severity of the present situation, with a curbing of the ongoing pandemic being of paramount importance for individuals and governments. However, the strong feelings evoked by the severity of the present situation may also be seen as a strength; a necessary condition in order to at all reveal the relative impact of the mechanisms tested. Acknowledging that contact-tracing apps aimed at fighting COVID-19 is only one specific subset of location-based services (including e.g. devices capturing driving-data for insurance purposes), the resemblance to other situations constitutes a strength of the study. The importance of the pro-social benefits could well be argued to hold also in other situations: the prosocial benefit of e.g. driving-data could be the achieving of safer roads for everyone, just as an example. A suggestion for future studies could hence be to model various situations, with different levels of criticality, against the pro-social component of the privacy calculus mechanism.

\section{References}

Bagozzi, R.P. (1975), "Marketing as exchange", fournal of Marketing, Vol. 39 No. 4, pp. 32-39.

Baruh, L., Secinti, E. and Cemalcilar, Z. (2017), "Online privacy concerns and privacy management: a meta-analytical review", fournal of Communication, Vol. 67 No. 1, pp. 26-53. 
Beke, F.T., Eggers, F. and Verhoef, P.C. (2018), “Consumer informational privacy: current knowledge and research directions", Foundations and Trends ${ }^{\circledR}$ in Marketing, Vol. 11 No. 1.

Birnbaum, M. and Spolar, C. (2020), "Coronavirus tracking apps meet resistance in privacy-conscious Europe", The Washington Post, 18 April.

Childers, T.L., Carr, C.L., Peck, J. and Carson, S. (2002), "Hedonic and utilitarian motivations for online retail shopping behavior", fournal of Retailing, Vol. 77 No. 4, pp. 511-535.

Council of Europe (2020), "Joint statement on digital contact tracing by Alessandra Pierucci, chair of the committee of convention 108 and Jean-Philippe Walter, data protection commissioner of the council of Europe", available at: https:// rm.coe.int/covid19-joint-statement-28-april/16809e3fd7

Culnan, M. (1993), "How did they get my name? An exploratory investigation of consumer attitudes toward secondary information use", MIS Quarterly, Vol. 17 No. 3.

Culnan, M. and Armstrong, P. (1999), "Information privacy concerns, procedural fairness and impersonal trust: an empirical investigation", Organization Science, Vol. 10 No. 1.

Culnan, M. and Bies, R. (2003), "Consumer privacy: balancing economic and justice considerations", fournal of Social Issues, Vol. 59 No. 2, pp. 323-342.

Davis, F.D. (1989), "Perceived usefulness, perceived ease of use, and user acceptance of information technology", MIS Quarterly, Vol. 13 No. 3, pp. 319-339.

de Kerviler, G., Demoulin, N.T.M. and Zidda, P. (2016), "Adoption of in-store mobile payment: are perceived risk and convenience the only drivers?", fournal of Retailing and Consumer Services, Vol. 31, pp. 334-344.

Dienlin, T. and Trepte, S. (2015), "Is the privacy paradox a relic of the past? An in-depth analysis of privacy attitudes and privacy behaviors", European fournal of Social Psychology, Vol. 45 No. 3, pp. 285 -297.

Dinev, T. and Hart, P. (2006), "An extended privacy calculus model for e-commerce transactions", Information Systems Research, Vol. 17 No. 1, pp. 61-80.

Dinev, T., Xu, H., Smith, J.H. and Hart, P. (2012), "Information privacy and correlates: an empirical attempt to bridge and distinguish privacy-related concepts", European Fournal of Information Systems, Vol. 22, pp. 61-80.

Franke, T., Christiane, A. and Daniel, W. (2019), "A personal resource for technology interaction: development and validation of the affinity for technology interaction (ATI) scale", International fournal of Human-computer Interaction, Vol. 35 No. 6, pp. 456-467.

Fuller, C.M., Simmering, M.J., Atinc, G., Atinc, Y. and Babin, B.J. (2016), "Common methods variance detection in business research", Fournal of Business Research, Vol. 69 No. 8, pp. 3192-3198.

Gupta, K. and Singh, N. (2014/15), "Fit estimation in structural equation modeling - a synthesis of related statistics”, HSB Research Review, Vol. 8 No. 2, pp. 20-27.

Hinch, R., Probert, W., Nurtay, A., Kendall, M., Wymant, C., Hall, M., Lythgoe, K., Bulas Cruz, A., Zhao, A., Stewart, A., Ferretti, L., Parker, M., Meroueh, A., Mathias, B., Stevenson, S., Montero, D., Warren, J., Mather, N., Finkelstein, A., Abeler-Dörner, L., Bonsall, D. and Fraser,
C. (2020), "Effective configurations of a digital contact tracing app: a report to NHSX", MedRxiv, 16 April.

Kline, R.B. (2005), Principles and Practice of Structural Equation Modeling, Guilford Press. New York, NY.

Lee, M.C. (2009), "Factors influencing the adoption of internet banking: an integration of TAM and TPB with perceived risk and perceived benefit", Electronic Commerce Research and Applications, Vol. 8 No. 3, pp. 130-141.

Lee, H., Park, H. and Kim, J. (2013), "Why do people share their context information on social network services? A qualitative study and an experimental study on users' behavior of balancing perceived benefit and risk", International fournal of Human-Computer Studies, Vol. 71 No. 9, pp. 862-877.

Malhotra, N., Kim, S. and Agarwal, J. (2004), “Internet users' information privacy concerns (IUIPC): the construct, the scale, and a causal model", Information Systems Research, Vol. 15 No. 4, pp. 336-355.

Martin, K.D. and Murphy, P.E. (2017), "The role of privacy in marketing", Fournal of the Academy of Marketing Science, Vol. 45 No. 2, pp. 135-155.

Mimouni-Chaabane, A. and Volle, P. (2010), "Perceived benefits of loyalty programs: scale development and implications for relational strategies", fournal of Business Research, Vol. 63 No. 1, pp. 32-37.

Muoio, D. (2020), "Bluetooth contact tracing apps built with google and apple's APIs still collect android users' location data", MobiHealthNews, 21 July.

Norberg, P., Horne, D.R. and Horne, D.A. (2007), "The privacy paradox: personal information disclosure intentions versus behaviors", fournal of Consumer Affairs, Vol. 41 No. 1, pp. 100-126.

Parayitam, S., Desai, K.J., Desai, M.S. and Eason, M.K. (2010), "Computer attitude as a moderator in the relationship between computer anxiety, satisfaction, and stress", Computers in Human Behavior, Vol. 26 No. 3, pp. 345-352.

Pavlou, P. and Chellappa, R. (2001), "The role of perceived privacy and perceived security in the development of trust in electronic commerce transactions", Information System Research, Vol. 11 No. 1, pp. 18-36.

Pizzi, G., Scarpi, D., Picchierri, M. and Vannucchi, V. (2019), "Virtual reality, real reactions? Comparing consumers' perceptions and shopping orientation across physical and virtual-reality retail stores", Computers in Human Behavior, Vol. 96, pp. 1-12.

Pomfret, L., Previte, J. and Coote, L. (2020), "Beyond concern: socio-demographic and attitudinal influences on privacy and disclosure choices", fournal of Marketing Management, Vol. 36 Nos 5/6, pp. 519-549.

Scarpi, D. (2012), "Work and fun on the internet: the effects of utilitarianism and hedonism online", fournal of Interactive Marketing, Vol. 26 No. 1, pp. 53-67.

Sharma, T. and Bashir, M. (2020), "Use of apps in the COVID-19 response and the loss of privacy protection", Nature Medicine, Vol. 26 No. 8, pp. 1165-1167.

Trang, T., Trenz, M., Weiger, W.H., Tarafdar, M. and Cheung, C.M.K. (2020), "One app to trace them all? Examining app specifications for mass acceptance of contacttracing apps”, European fournal of Information Systems, Vol. 29 No. 4, pp. 415-428. 
Venkatesh, V., Thong, J.Y. and Xu, X. (2012), “Consumer acceptance and use of information technology: extending the unified theory of acceptance and use of technology", MIS Quarterly, Vol. 36 No. 1, pp. 157-178.

Wang, L., Hu, H.-H., Yan, J. and Mei, M.Q. (2020), "Privacy calculus or heuristic cues? The dual process of privacy decision making on Chinese social media", fournal of Enterprise Information Management, Vol. 33 No. 2, pp. 353-380.

White, K. and Peloza, J. (2009), "Self-benefit versus otherbenefit marketing appeals: their effectiveness in generating charitable support", fournal of Marketing, Vol. 73 No. 4, pp. 109-124.

Wottrich, V.M., Reijmersdal, E.A. and Smit, E.G. (2019), "App users unwittingly in the spotlight: a model of privacy protection in mobile apps", Fournal of Consumer Affairs, Vol. 53 No. 3, pp. 1056-1083.

Xu, H., Dinev, T., Smith, J. and Hart, P. (2011), "Information privacy concerns: linking individual perceptions with institutional privacy assurances", fournal of the Association for Information Systems, Vol. 12 No. 12.

Zastrow, M. (2020), "Corona-virus contact-tracing apps: can they slow the spread of COVID-19?", Nature, 19 May.

Zhao, L., Lu, Y. and Gupta, S. (2012), "Disclosure intention of location-related information in location-based social network services", International foumal of Electronic Commerce, Vol. 16 No. 4, pp. 53-90.

\section{Further reading}

Kwee-Meier, S.T., Bützler, J.E. and Schlick, C. (2016), "Development and validation of a technology acceptance model for safety-enhancing, wearable locating systems", Behaviour $\mathcal{E}$ Information Technology, Vol. 35 No. 5, pp. 394-409.

\section{Corresponding author}

Jeanette Carlsson Hauff can be contacted at: jeanette. hauff@handels.gu.se

For instructions on how to order reprints of this article, please visit our website: 